\title{
External cephalic version for breech presentation at term: predictors of success, and impact on the rate of caesarean section
}

O.A. Hussin, ${ }^{1}$ M.A. Mahmoud ${ }^{1}$ and M.M. Abdel-Fattah ${ }^{2}$

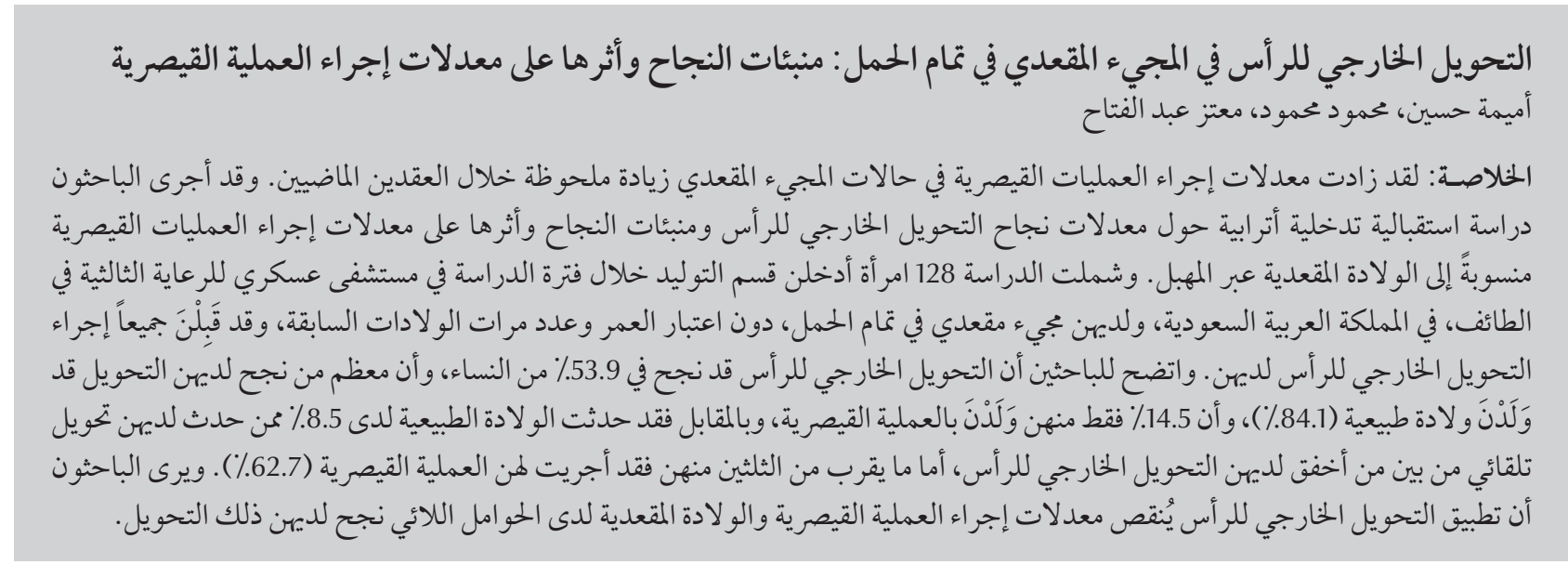

ABSTRACT The incidence of caesarean section for breech presentation has increased markedly in the last 20 years. A prospective, interventional cohort study was carried out of the success rate of external cephalic version (ECV) and its predictors of as well as its impact on the rate of caesarean section for vaginal breech delivery. All 128 women admitted during the study period to the obstetrics department of a tertiary care military hospital in Taif, Saudi Arabia with breech presentation at term, regardless of age and parity, who accepted ECV were recruited. ECV was successful in 53.9\% of the women. Most of the women with successful ECV delivered normally (84.1\%) and only $14.5 \%$ of them delivered by caesarean section. Conversely, normal vaginal delivery was reported among 8.5\% of those who had spontaneous version with failed ECV and approximately two-thirds of them delivered by caesarean section (62.7\%). Successful ECV reduced the breech and caesarean section rate.

Version céphalique externe en cas de présentation par le siège à terme : facteurs prédictifs de succès et impact sur le taux de césariennes

RÉSUMÉ L'incidence des césariennes en cas de présentation par le siège a beaucoup augmenté au cours des 20 dernières années. Une étude interventionnelle d'une cohorte prospective a été menée pour connaître le taux de succès des versions céphaliques externes et ses facteurs prédictifs, ainsi que l'impact sur le taux de césariennes par rapport à l'accouchement du siège par voie vaginale. Les 128 femmes qui ont été admises pendant l'étude au service d'obstétrique de l'hôpital militaire de soins de santé tertiaires à Taif(Arabie saoudite) pour une présentation par le siège à terme, et qui ont accepté une version céphalique externe ont toutes été recrutées indépendamment de leur âge et du nombre de leurs accouchements. La version céphalique externe a été un succès chez 53,9\% de ces femmes. La plupart des femmes pour qui la version céphalique externe a été un succès ont accouché par voie basse ( $84,1 \%)$ et seules $14,5 \%$ d'entre elles ont accouché par césarienne. À l'inverse, un accouchement par voie basse a été rapporté chez 8,5\% des femmes ayant eu une version spontanée après un échec de la version céphalique externe et environ deux tiers d'entre elles ont accouché par césarienne (62,7\%). Le succès dans la version céphalique externe permettait de réduire le taux de présentation par le siège et le taux de césariennes chez les femmes.

${ }^{I}$ Department of Gynaecology and Obstetrics; ${ }^{2}$ Department of Preventive Medicine (Research Unit), Al-Hada Armed Forces Hospital, Taif, Saudi Arabia (Correspondence to M.M. Abdel-Fattah:mezo106@yahoo.com; mezo106@gmail.com).

Received: 31/10/11; accepted: 21/02/12 


\section{Introduction}

Breech presentation complicates $3 \%-4 \%$ of all term deliveries [1]. It has been widely recognized that there is higher perinatal morbidity with breech presentation, due principally to prematurity, congenital malformations, birth asphyxia and birth trauma [1]. Breech presentation, whatever the mode of delivery, is a signal for potential fetal handicap and this should be communicated to the mother during antenatal, intrapartum and neonatal management [2]. The incidence of caesarean section for breech presentation has increased markedly in the last 20 years [3]. The Term Breech Trial concluded that, at least for mortality and markers of intermediate term morbidity, elective caesarean section was safer for the fetus and of similar safety to the mother when compared with intention to deliver vaginally [4-6]. This means that measures to reduce the incidence of breech presentation have become more important and that the effect of any such measure on the incidence of caesarean section will be more evident [1].

External cephalic version (ECV) at or near to term is a safe procedure which could effectively reduce the incidence of caesarean section in breech pregnancies [1]. ECV has been subjected to rigorous scientific appraisal in more than 6 randomized controlled studies. There is a significant reduction in the incidence of caesarean section in women where there is an intention to undertake ECV without any increased risk to the baby [7]. Routine use of ECV could reduce the rate of caesarean delivery by about two-thirds [8]. It is recommended that all women with an uncomplicated breech pregnancy at term (37-42 weeks) should be offered ECV $[1,9]$. Although primarily intended for uncomplicated breech pregnancies at term, ECV has been carried out successfully in previous caesarean sections $[10,11]$ and during early labour [7].
The current study aimed to study the success rate of ECV and its predictors in a tertiary care setting as well as its impact on reducing the rate of caesarean section for breech presentation and vaginal breech delivery.

\section{Methods}

\section{Study setting and sample}

In a prospective, interventional cohort study all women admitted to the obstetric department of Al-Hada Armed Forces Hospital (a tertiary care hospital with 360 beds) in Taif, Saudi Arabia, during the period June 2008 to June 2010, regardless of age and parity, with breech presentation at term were included in the study. Inclusion criteria were women with gestation of 37 weeks and onwards with breech presentation regardless of age and parity, who accepted ECV. The exclusion criteria were refusal of ECV, multiple pregnancy, severe intrauterine growth retardation, severe amniotic fluid abnormalities, placenta previa, significant third trimester bleeding, uterine malformation, uncontrolled hypertensive disorders, major fetal anomalies, non-reassuring cardiotocography and any indication for caesarean section.

\section{Data collection}

Each patient was instructed to present to the labour ward in a fasting state, and an initial cardiotocography was done. A clinical assessment as well as bedside ultrasound scan was performed by the operator to confirm the fetal presentation. The degree of fetal flexion and the position of the fetal back were noted. Tocolysis was given to patients with irritable uterus and the procedure was done 1 hour later.

The ECV procedure included dislodging the fetal breech from the pelvis while holding the fetus in a flexed position with both hands, turning the breech away from the pelvis. After completion of the procedure another ultrasound was done to confirm the presentation and a cardiotography was repeated. Patients were discharged with a documented plan of delivery.

The rates of successful ECV, normal spontaneous vaginal delivery after successful ECV, caesarean section after attempted ECV and ECV-related fetal complications (bradycardia, emergency caesarean section or spontaneous rupture membrane during the procedure) were computed as outcome measures. The variables included in the study were: success of ECV, complications, presentation in labour, mode of delivery, fetal outcome (Apgar score $<7$ at 5 minutes) and length of post-delivery hospital stay.

\section{Statistical analysis}

Data were analysed using SPSS, version 13 and Epi-info, version 3.3.2. The chisquared test was used to compare 2 or more qualitative variables. Failed ECV was treated as the dependent variable in both bivariate and logistic regression analysis. Age, parity, position of the placenta, fetal weight, maximum pool depth of amniotic fluid and tocolysis were treated as independent categorical variables. Bivariate data analysis was performed and expressed as crude odds ratio (OR) and their 95\% confidence intervals (CI). Multiple associations were evaluated in a multiple logistic regression model based on the backward stepwise selection, where significant variables from the univariate analysis were included. The adjusted measure of association between risk factors and failed ECV was expressed as the OR with 95\% CI. Adjusted or crude ORs with 95\% CI that did not include 1.0 were considered significant.

\section{Results}

For the 128 women recruited to the study the mean age was 30.1 (SD 6.7) years with a minimum of 17 years and a maximum of 46 years. 


\section{Mode of delivery and duration of hospitalization}

ECV succeeded in more than half of cases $(69,53.9 \%)$. Most of the women with successful ECV delivered normally ( $84.1 \%$ ), while only $14.5 \%$ of them delivered by caesarean section. Conversely, normal vaginal delivery was reported among only $8.5 \%$ of those who had spontaneous version with failed ECV and nearly two-thirds of them delivered by caesarean section (62.7\%). Vaginal breech delivery was reported in $27.1 \%$ of women with failed ECV compared with none of those with successful ECV (as all of them remained with cephalic fetal presentation until delivery). The difference between the 2 groups was statistically significant $(P<0.001)$ (Table 1).

Among those with successful ECV, almost two-thirds stayed for only 1 day in the hospital postdelivery (63.8\%) as compared with $28.8 \%$ among those with failed ECV. On the other hand, only $13.0 \%$ of women with successful ECV stayed $>3$ days in the hospital post-delivery compared with $37.3 \%$ among those with failed ECV. This difference was statistically significant $(P<0.001)$ (Table 1).

\section{Variables associated with failed ECV}

Multivariate logistic regression analysis was performed to predict independent variables associated with failed ECV. Age $(25-35,<25$ versus $<35$ years old), parity ( $1-3,0$ versus $>3)$, placental position (fundal, anterior versus posterior), fetal weight ( $>3 \mathrm{~kg}$ versus $\leq 3 \mathrm{~kg}$ ), maximum pool depth of amniotic fluid $(<4.6 \mathrm{~mm}$ versus $\geq 4.6$ $\mathrm{mm}$ ) and tocolysis (used versus not used) were included in the bivariate and multivariate regression analyses.

In the multivariate analysis, primigravida were significantly more likely to be associated with failed ECV as opposed to those with parity $>3$ (adjusted $\mathrm{OR}=3.17,95 \% \mathrm{CI}: 1.08-7.01)$. On the other hand, women presenting with anterior placenta were significantly more likely to have failed ECV than those presenting with posterior placenta (adjusted $\mathrm{OR}=2.10,95 \% \mathrm{CI}: 1.01-5.17$ ). Regarding the amount of amniotic fluid, patients with maximum pool depth < $4.6 \mathrm{~cm}$ had almost double the risk for failed ECV compared with those having maximum pool depth $\geq 4.6 \mathrm{~cm}$ (adjusted $\mathrm{OR}=1.99,95 \% \mathrm{CI}: 1.04-4.58$ ). However, maternal age, fetal weight and tocolysis showed no significant association with failed ECV (Table 2).
None of the studied fetal complications-bradycardia, emergency caesarean section, spontaneous rupture of membranes and low Apgar score $(<5$ at 5 minutes) —-were reported.

\section{Discussion}

The overall success rate of ECV in studies published in the United Kingdom was $46 \%[12,13]$. Among published studies in the Untied States it reached $65 \%[1]$ and $69.5 \%$ in a recent study $[8]$. In a study conducted at a tertiary teaching hospital in Malaysia, involving 41 pregnant women with malpresentation at term, ECV was successful in $63 \%$ of women [14]. In our study of women with breech presentation at term, the success rate was $53.9 \%$

Most of the reports in the medical literature that were predictive of the outcome of ECV were limited by small sample sizes, with conflicting results. Univariate analysis predominated in these reports, but this does not exclude the possibility of confounding effect between the variables [15-18].

A variety of factors have been associated with ECV success in the literature. Newman et al. [19], using linear regression analysis, found that

\begin{tabular}{|c|c|c|c|c|c|}
\hline \multirow[t]{3}{*}{ Variables } & \multicolumn{4}{|c|}{ External cephalic version } & \multirow[t]{3}{*}{$P$-value ${ }^{\text {a }}$} \\
\hline & \multicolumn{2}{|c|}{$\begin{array}{l}\text { Successful } \\
(n=69)\end{array}$} & \multicolumn{2}{|c|}{$\begin{array}{c}\text { Failed } \\
(n=59)\end{array}$} & \\
\hline & No. & $\%$ & No. & $\%$ & \\
\hline \multicolumn{6}{|l|}{ Mode of delivery } \\
\hline Normal vaginal & 58 & 84.1 & 5 & 8.5 & \\
\hline Instrumental & 1 & 1.4 & 1 & 1.7 & \\
\hline Breech & 0 & 0.0 & 16 & 27.1 & \\
\hline Caesarean & 10 & 14.5 & 37 & 62.7 & $<0.001$ \\
\hline \multicolumn{6}{|c|}{$\begin{array}{l}\text { Duration of post-delivery } \\
\text { hospitalization (days) }\end{array}$} \\
\hline 1 & 44 & 63.8 & 17 & 28.8 & \\
\hline $2-3$ & 16 & 23.2 & 20 & 33.9 & \\
\hline$>3$ & 9 & 13.0 & 22 & 37.3 & $<0.001$ \\
\hline
\end{tabular}

${ }^{a}$ Chi-squared test. 


\begin{tabular}{|c|c|c|c|c|c|c|}
\hline \multirow[t]{3}{*}{ Variables } & \multicolumn{4}{|c|}{ External cephalic version } & \multirow[t]{3}{*}{ Crude OR $(95 \% \mathrm{CI})$} & \multirow[t]{3}{*}{ Adjusted OR $(95 \% \mathrm{Cl})$} \\
\hline & \multicolumn{2}{|c|}{$\begin{array}{l}\text { Successful } \\
(n=69)\end{array}$} & \multicolumn{2}{|c|}{$\begin{array}{c}\text { Failed } \\
(n=59)\end{array}$} & & \\
\hline & No. & $\%$ & No. & $\%$ & & \\
\hline \multicolumn{7}{|l|}{ Age (years) } \\
\hline$>35^{\mathrm{a}}$ & 20 & 29.0 & 13 & 22.0 & 1 & $-{ }^{b}$ \\
\hline $25-35$ & 33 & 47.8 & 29 & 49.2 & $1.35(0.53-3.49)$ & \\
\hline$<25$ & 16 & 23.2 & 17 & 28.8 & $1.63(0.55-4.89)$ & \\
\hline \multicolumn{7}{|l|}{ Parity } \\
\hline$>3^{\mathrm{a}}$ & 29 & 42.0 & 19 & 32.2 & 1 & 1 \\
\hline $1-3$ & 28 & 40.6 & 21 & 35.6 & $1.14(0.47-2.79)$ & $1.56(0.62-3.12)$ \\
\hline 0 & 12 & 17.4 & 19 & 32.2 & $2.42(0.87-6.80)$ & $3.17(1.08-7.01)$ \\
\hline \multicolumn{7}{|c|}{ Placental position } \\
\hline Posterior $^{\mathrm{a}}$ & 36 & 52.2 & 21 & 35.6 & 1 & \\
\hline Fundal & 10 & 14.5 & 7 & 11.9 & $1.20(0.35-4.12)$ & $0.85(0.41-4.06)$ \\
\hline Anterior & 23 & 33.3 & 31 & 52.5 & $2.31(1.01-5.33)$ & $2.10(1.01-5.17)$ \\
\hline \multicolumn{7}{|c|}{ Fetal weight (kg) } \\
\hline$\leq 3^{\mathrm{a}}$ & 53 & 76.8 & 44 & 74.6 & 1 & $-{ }^{b}$ \\
\hline$>3$ & 16 & 23.2 & 15 & 25.4 & $1.13(0.47-2.74)$ & \\
\hline \multicolumn{7}{|c|}{ Amniotic fluid MPD $(\mathrm{cm})^{c}$} \\
\hline$\geq 4.6^{\mathrm{a}}$ & 41 & 59.4 & 23 & 39.0 & 1 & 1 \\
\hline$<4.6$ & 28 & 40.6 & 36 & 61.0 & $2.29(1.06-4.97)$ & $1.99(1.04-4.58)$ \\
\hline \multicolumn{7}{|l|}{ Tocolysis } \\
\hline Not used $^{\mathrm{a}}$ & 56 & 81.2 & 43 & 72.9 & 1 & $-{ }^{b}$ \\
\hline Used & 13 & 18.8 & 16 & 27.1 & $1.60(0.65-4.00)$ & \\
\hline
\end{tabular}

${ }^{a}$ Reference category; ${ }^{b}$ Removed from final model; ' Based on median cut-off value. $O R=$ odds ratio; $\mathrm{Cl}=$ confidence interval; $M P D=$ maximum pool depth .

parity, cervical dilatation, estimated fetal weight, breech station and placental implantation site were the most useful predictors of ECV success. Maternal weight, gestational age, type of breech, amniotic fluid volume and cervical effacement did not have a significant effect. The present study found that the amount of amniotic fluid had an almost significant but non-linear effect on success rate, which may explain why linear regression analysis excluded it in $\mathrm{New}$ man's study. In our population, a 48.2\% lower caesarean section rate and $27.1 \%$ lower vaginal breech delivery rate was seen in cases of successful ECV of term breeches. Each attempted ECV took from 5-10 minutes of operator time, preceded and followed by cardiotocography for 40 minutes. Use of ECV as a method for reduction of term breech caesarean section rates is therefore very labour intensive.

It has been reported that the use of tocolytic agents increased the success rate of ECV, both when used routinely and when used selectively $[7,13]$. In our study, the use of tocolytic agents was not significantly associated with successful ECV, perhaps due to the small sample size. Two other small prospective trials showed no benefit of tocolysis in ECV [20,21].

Around 3 to 5 days in the hospital is the common length of stay following caesarean birth, whereas it is less than 1-3 days for a vaginal birth [22]. In accordance with these data, our study revealed that successful ECV was significantly associated with shorter hospital stays.

Offering an ECV service reduced the breech delivery rate and caesarean section rate in women with successful ECV. Nevertheless, if ECV is to make an impact on breech vaginal deliveries and caesarean sections, efforts must be made to expand the suitability criteria for ECV and increase the success rate of ECV, without increasing the morbidity and mortality (both maternal and perinatal) associated with the procedure.

\section{Acknowledgements}

We would like to thank all physicians, midwives and nurses in the department of obstetrics and gynaecology who participated in diagnosing, referring and counselling of patients. We would also thank members of research unit for their advice and help throughout preparation of this work. 


\section{References}

1. External cephalic version (ECV) and reducing the incidence of breech presentation (Green-top Guideline 20a). London, Royal College of Obstetricians and Gynaecologists, 2006.

2. Danielian PJ, Wang J, Hall MH. Long term outcome by method of delivery of fetuses in breech presentation at term: population based follow up. British Medical Journal, 1996, 312:14511453.

3. Rietberg CC, Elferink-Stinkens PM, Visser GH. The effect of the Term Breech Trial on medical intervention behaviour and neonatal outcome in The Netherlands: an analysis of 35,453 term breech infants. British Journal of Obstetrics and Gynaecology, 2005, 112:205-209.

4. Hannah ME et al.; Term Breech Trial Collaborative Group. Planned caesarean section versus planned vaginal birth for breech presentation at term: a randomised multicentre trial. Lancet, 2000, 356:1375-1383.

5. Hofmeyr GJ, Hannah ME. Planned caesarean section for term breech delivery. Cochrane Database of Systematic Reviews, 2003, (3):CD000166.

6. Cunningham FG et al. Breech presentation and delivery. In: Williams' obstetrics, 23rd ed. New York, McGraw-Hill, 2010:527-543.

7. Hofmeyr GJ, Kulier R. External cephalic version for breech presentation at term. Cochrane Database of Systematic Reviews, 2000, (2):CD000083.

8. Zhang J, Bowes EA, Fortney JA. Efficacy of external cephalic version: a review. Obstetrics and Gynecology, 1993, 82:306-312.

9. Lau TK et al. Predictors of successful external cephalic version at term: a prospective study. British Journal of Obstetrics and Gynaecology, 1997, 104:798-802.

10. Shalev E, Battino S, Giladi Y. External cephalic version at term using tocolysis. Acta Obstetricia et Gynecologica Scandinavica, 1993, 72:455-457.

11. Flamm BL et al. External cephalic version after caesarean section. American Journal of Obstetrics and Gynecology, 1991, 165:370-372.
12. Bewley $S$ et al. The introduction of external cephalic version at term into routine clinical practice. European Journal of $\mathrm{Ob}$ stetrics, Gynecology, and Reproductive Biology, 1993, 52:89-93.

13. Breech presentation, management (Green-top Guideline 20b). London, Royal College of Obstetricians and Gynaecologists, 2001.

14. Yong SPY. Introducing external cephalic version in a Malaysian setting. Hong Kong Medical Journal, 2007, 13:40-45.

15. Brocks V, Philipsen T, Secher NJ. A randomized trial of external cephalic version with tocolysis in late pregnancy. British Journal of Obstetrics and Gynaecology, 1984, 91:653-656.

16. Donald WL, Barton JJ. Ultrasonography and external cephalic version at term. American Journal of Obstetrics and Gynecology, 1990, 162:1542-1545.

17. Shalev E et al. External cephalic version at term-using tocolysis. Acta Obstetricia et Gynecologica Scandinavica, 1993, 72:455-457.

18. Klatt TE, Cruikshank DP. Breech, other malpresentations, and umbilical cord complications. In: Gibbs RS, et al., eds. Danforth's Obstetrics and Gynecology, 10th ed. Philadelphia, Lippincott Williams and Wilkins, 2008:400-416.

19. Newman RB et al. Predicting success of external cephalic version. American Journal of Obstetrics and Gynecology, 1993, 169:245-249.

20. Robertson AW et al. External cephalic version at term: is a tocolytic necessary? Obstetrics and Gynecology, 1987, 70:896-899.

21. Tan GWT et al. A prospective randomised controlled trial of external cephalic version comparing two methods of uterine tocolysis with a non-tocolysis group. Singapore Medical Journal, 1989, 30:155-158.

22. Santrock JW, Brown WC. Child development, 6th ed. Madison, Wisconsin, Brown and Benchmark, 1994. 